Education

et sociétés

plurilingues

\section{Éducation et sociétés plurilingues}

39 | 2015

Varia

\title{
Langues régionales et minoritaires
}

Informations pédagogiques

\section{Geneviève Paulet}

\section{(2) OpenEdition}

\section{Journals}

Édition électronique

URL : http://journals.openedition.org/esp/680

DOI : $10.4000 /$ esp.680

ISSN : 2532-0319

Éditeur

Centre d'Information sur l'Éducation Bilingue et Plurilingue

Édition imprimée

Date de publication : 1 décembre 2015

Pagination : 105-107

ISSN : 1127-266X

Référence électronique

Geneviève Paulet, «Langues régionales et minoritaires », Éducation et sociétés plurilingues [En ligne], 39 | 2015, mis en ligne le 01 octobre 2016, consulté le 15 septembre 2020. URL : http:// journals.openedition.org/esp/680 


\section{LANGUES RÉGIONALES ET \\ MINORITAIRES. INFORMATIONS \\ PÉDAGOGIQUES}

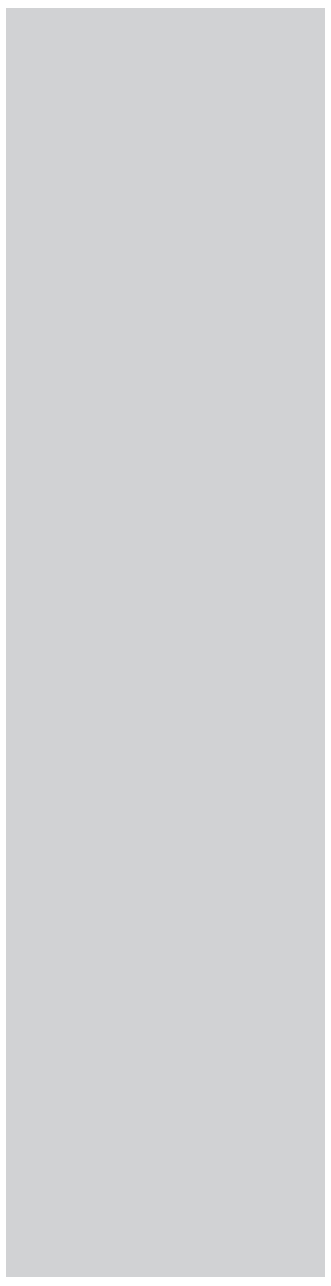

\section{Geneviève PaUlet}

Depuis plus de vingt ans, l'A.D.Oc., Association pour le Développement de l'Occitan, située à Mende dans le département de la Lozère, organise tous les cinq ans un colloque international. Ces rencontres portent sur l'enseignement des langues régionales et des langues minoritaires en France mais aussi hors de ses frontières.

L'enseignement de l'occitan dans le premier degré (maternelle et élémentaire) peut être dispensé sous la forme d'une initiation, d'un enseignement en tant que langue vivante ou d'un bilinguisme à parité horaire avec la langue française. Dans l'académie de Montpellier, le premier site bilingue de l'enseignement public s'implanta dans la ville de Mende en 1998.

Cette association, très impliquée dans l'enseignement de l'occitan, a toujours su développer en son sein des recherches et des formations pédagogiques pour aider les enseignants dans leurs pratiques de classe.

L'édition d'outils didactiques favorise le développement de la langue régionale occitane dans l'espace académique.

Les services de l'inspection de l'Éducation Nationale de la Lozère sont de plus en plus étroitement associés à ces colloques.

Le Conseiller Pédagogique Départemental en Langue et Culture régionales- occitan- en charge de cette action, joue le rôle de trait d'union entre l'institution et l'association.

La thématique retenue tient compte des préoccupations rencontrées par les enseignants.

C'est ainsi qu'en relisant les intitulés des colloques, l'on peut noter les différentes problématiques qui ont été au cœur des débats et des communications (1). Ils nous renseignent sur l'évolution des pratiques d'enseignement des langues à l'école; l'initiation, l'enseignement en tant que langue vivante, le bilingue, le bi-plurilingue.

Il est à remarquer également la place grandissante que jouent les langues dans l'apprentissage et l'acquisition des connaissances 
Langues régionales et minoritaires. Informations pédagogiques

G. PAulet non-linguistiques. Le développement de l'enseignement bi- plurilingue revêt une importance éducative qui peut être une réponse aux changements dans nos sociétés plurielles et multiculturelles, pour une meilleure gestion des langues et des cultures de tous les élèves.

Cet enseignement semble devoir s'accompagner d'une dimension culturelle telle que formulée par l'Éducation Nationale mais aussi par les différentes autorités territoriales, qui structurent l'espace socioculturel.

L'A.D.Oc., à travers les différents colloques organisés et notamment le dernier, souhaite mettre l'accent sur différents points qui interpellent les enseignants travaillant avec une langue qui est minoritaire et/ou minorisée dans leur environnement. C'est ainsi que la thématique du $5^{\text {eme }}$ colloque international du 20 au 22 octobre 2013 à Mende - Lozère - fut Transmissions linguistiques et culturelles, pratiques plurilingues.

Durant ce colloque, l'association A.D.Oc. a souhaité:

- Mettre en place un débat de fond pendant deux jours sur la problématique de la transmission de la langue et de la culture des langues minoritaires, régionales et plus particulièrement de l'occi$\tan$.

- Donner aux langues les moins répandues un espace de réflexion afin de les valoriser.

- Faire prendre conscience de la richesse et l'enjeu que représentent les langues régionales dans la diversité linguistique et culturelle.

- Réunir divers acteurs ayant en charge des fonctions différentes, mais néanmoins complémentaires et qui œuvrent dans la transmission linguistique et culturelle des langues minoritaires, régionales: élus, chercheurs, spécialistes de renommée mondiale: enseignants, associations, représentants de la culture, du patrimoine et des langues régionales.

- Permettre à des enseignants de terrain de présenter leurs pratiques pédagogiques, leurs productions et d'échanger avec des spécialistes et différents acteurs de la langue et de la culture afin d'améliorer et de mutualiser leurs pratiques. Enseignants bilingues de l'académie de Montpellier mais aussi de différentes académies de la France (Alsace, Bretagne, Catalogne, Corse, Pays Basque, Occitanie) et des pays européens: Suisse, Italie, et aussi le Canada.

Participent à cet effort collectif des spécialistes, chercheurs, universitaires dans le domaine de la linguistique, de la sociologie, de la formation des enseignants, venus de différentes universités afin 


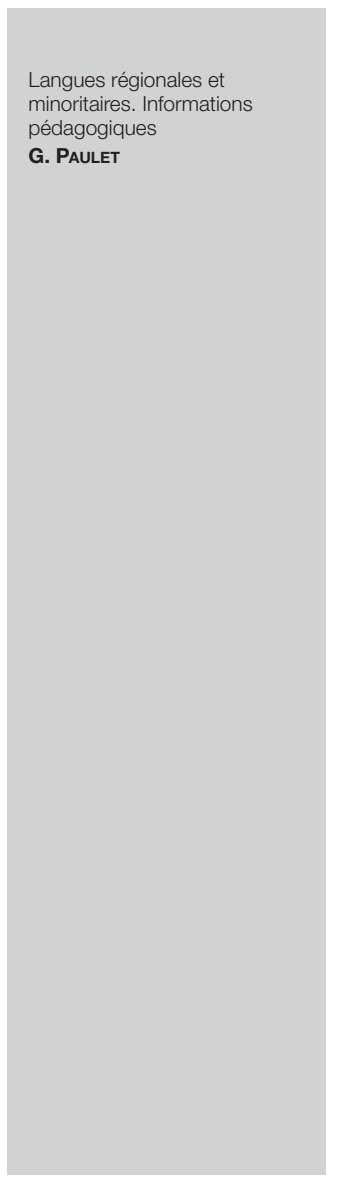

d'apporter des pistes de réflexions, de présenter leurs travaux en lien avec la thématique et ainsi de croiser leurs points de vue.

Cette thématique incluant diverses pistes de réflexion a été abordée selon différents dispositifs organisationnels pour valoriser les échanges. Se sont succédé conférences, ateliers, table ronde autant de contextes où les échanges furent privilégiés.

Afin de fixer dans le temps ces moments riches en interventions, apports théoriques, didactiques, l'A.D.Oc. a édité les actes du colloque de 2013 (2). Chaque texte est accompagné de son PowerPoint sur clé USB. Fixer ainsi les interventions, les discussions à travers des actes, c'est permettre de diffuser cette réflexion sur un espace plus large.

Qu'ils soient un outil de formation, de réflexion didactique pour l'enseignement des langues régionales ou minoritaires.

Qu'ils apportent chez les différents acteurs territoriaux une approche singulière dans l'aménagement de leurs territoires. Qu'ils permettent une meilleure prise en compte des langues, des cultures régionales, dans l'espace dont ils ont la charge.

\section{NOTES}

(1) "Enseignement des langues régionales en Europe dans les écoles publiques", Mende, 2729 octobre 1993. "Langues moins répandues en Europe et Enseignement", Mende, 27-30 octobre 1998. "Didactiques des langues régionales: De l'initiation au bilinguisme", Mende, 28-31 octobre 2003. "Passeport pour le plurilinguisme: Les mécanismes de l'apprentissage", Mende, 27-30 octobre 2008. «Transmissions linguistiques et culturelles - Pratiques plurilingues», Mende-Lozère, 20-22 octobre 2013.

(2) 5ème colloque international. Transmissions linguistiques et culturelles. Pratiques plurilingues. Mende, Lozère (48) Espace Jean Jaurès, 1 rue Charles Morel, 48000 Mende, 48adoc@gmail.com 